\title{
Japan eyes plans for robot-built Moon base
}

Tokyo. Determined not to be caught flatfooted if the international Space Station planned by the US National Aeronautics and Space Administration (NASA) finally gets the axe, the Japanese have made a counter-proposal. A report just published in Tokyo calls for Japan to construct a manned lunar base by the year 2024 .

Construction would be carried out in three phases over 30 years, at a cost of around $¥ 2,900$ (US $\$ 30$ billion). The main idea is that the Moon base would be built entirely by robots, exploiting Japan's advanced automation technology. Materials would be ferried to the site using $87 \mathrm{H}-\mathrm{II}$ rockets, Japan's indigenous launch vehicle, which had its successful maiden flight in February.

The first phase of the project, from 1999 to 2005 , would land a lunar rover to survey possible landing sites. During the second phase, from 2006 to 2016 , pilot plants would be constructed for the production of food, oxygen and energy. The final phase, from 2017 to 2023 , would see the building of fullscale facilities, including living quarters for people.

The proposal includes a permanent staff of six. International partners would be welcome, but - significantly - are not seen as an essential pre-condition, a reflection of Japan's frustration over its involvement in international projects in the recent past.

The proposal comes from the newlyformed Lunar and Planetary Society, a thinktank whose members include academics, government researchers and engineers from 20 of Japan's largest heavy engineering and construction companies. The society was established to follow up a large-scale study on lunar exploration and exploitation sponsored by the Institute for Future Technology, an independent non-profit organization, and carried out between 1989 and 1991.

The principal advocate of the proposal is Ryojiro Akiba, director-general of Japan's Institute of Space and Astronautical Science (ISAS). But according to Nobuki Kawashima, who represents ISAS on the steering committee of the Lunar and Planetary Society, Akiba is acting as an independent individual, not in his official capacity.

The reason for the distinction, explains Kawashima, is that "scientists at ISAS are still very cool" towards the plans for a lunar base. "When we discuss lunar base construction, every time the question arises, what is it for?" he says.

Another question that is difficult to answer is whether the plan is feasible. Until now, the general consensus has been that the construction of a lunar base would cost at least $¥ 29$ trillion. The Japanese report says that unmanned, robotic construction can be used to reduce the price by an order of magnitude, to $¥ 2.9$ trillion.

But the plan is also based on the use of the $\mathrm{H}$-II rocket, considered to be by far the most expensive launch vehicle in the world. "If we use the current $\mathrm{H}-\mathrm{II}$, it is inconceivable that we meet the proposed budget," Kawashima concedes.

Despite such discrepancies, the lunar base proposal is said to have been greeted favourably by members of the Space Activities Commission, the body that makes recommendations on space policy to the Japanese government's Science \& Technology Agency. Japan reviews its space policy every five years, and it is up for review this year. A decision on whether officially to adopt the lunar base proposal is expected in the autumn.

Bob Johnstone

\section{Sex discrimination among India's engineers confirmed}

New Delhi. Women engineers in India face discrimination from the time they enter engineering colleges, and it continues throughout their careers, according to a government-sponsored study. Not only are they treated differently from their male counterparts during their training, but many industrial companies still treat them as misfits, only giving them jobs for which there are no male applicants.

The two-year study was sponsored by the Department of Science and Technology (DST), and carried out by Mrs P. P. Parikh and S. P. Suhatme, professors in the mechanical engineering department of the Indian Institute of Technology in Bombay. It urges women engineers to form a separate organization to defend their rights.

The need for the study originated in the rapid increase in women engineers in India over the past 15 years. There were fewer than 1,000 in 1975 , but by 1990 the figure had risen to 19,180 , and it is expected to reach 53,000 by 1996 .

As numbers started to rise rapidly, personal and career problems began to surface, say the two authors. Having identified more than 16,000 women engineers, the authors sent out questionnaires to 5,000 of them, and received replies from 2,753.

These provided examples of the different types of discrimination in engineering colleges. For example, the study found that female students are often denied the project of their choice by male teachers, and required to take summer courses in 'design training', as companies are reluctant to give them practical experience on the shop floor. In one college, the three women in a class of 70 were even excluded from industrial tours.

Problems escalate when woman engineering graduates start to look for jobs. Campus interviews are often restricted to

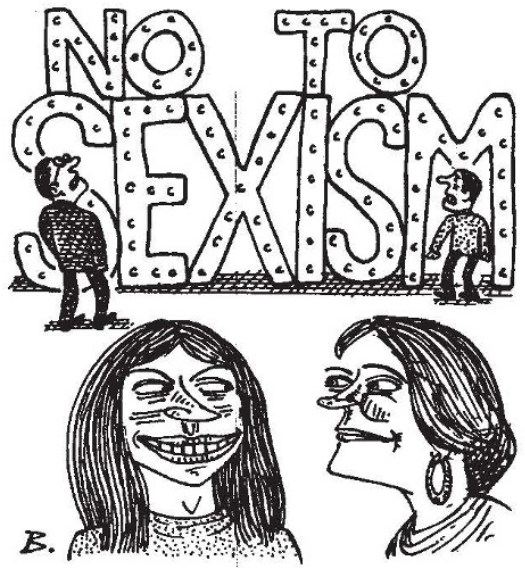

men, and many companies openly declare that women need not apply.

If called for interviews, women face questions such as: "How will you manage both family and job?" A female graduate from
Kerala University eventually became an office clerk at US\$40 a month after she failed to get a job as an engineer after three interviews.

Partly for these reasons, unemployment among female engineers is 26 per cent about five times higher than among males.

As a result of discrimination, many women engineers are forced to take teaching jobs, or to join the civil service. The problem is repeated in private industry, where women make up 20 per cent of the workforce, but nearly 60 per cent carry out secretarial or administrative duties.

Despite recent signs of improvement, many women engineers "feel they are not getting what they deserve in terms of promotions, salaries, as well as professional recognition and incentives", the report concludes.

It proposes two strategies to improve their status. The first is to increase the number of women enrolling in engineering colleges through 'awareness programmes' for teachers and parents and an increase in the number of places available for women.

The second would be to include women on interview boards, and to establish a minimum quota of women in engineering companies, if necessary enforced through legislation. The National Commission on Women has agreed to set up a separate body to ensure that these recommendations are implemented.

K. S. Jayaraman 